\title{
Relevant aspects regarding the characteristics of the parents and progenies for artificial hybridization of soybean
}

\author{
M.H. Barbosa ${ }^{1}$, I.R. Carvalho ${ }^{2}$, V.J. Szareski ${ }^{1}$, F. Lautenchleger ${ }^{3}$, \\ J.A.G. da Silva ${ }^{2}$, D.A. Magano ${ }^{2}$, J.P. Sangiovo ${ }^{2}$, E.M. Matter ${ }^{2}$, \\ L.L. Ferreira ${ }^{4}$ and V.Q. de Souza ${ }^{5}$ \\ ${ }^{1}$ Universidade Federal de Pelotas, Capão do Leão, RS, Brasil \\ ${ }^{2}$ Universidade Regional do Noroeste do Estado do Rio Grande do Sul, Ijuí, \\ RS, Brasil \\ ${ }^{3}$ Universidade do Centro-Oeste (Unicentro), Guarapuava, PR, Brasil \\ ${ }^{4}$ Centro Universitário de Mineiros, Mineiros, GO, Brasil \\ ${ }^{5}$ Universidade Federal do Pampa (PQ 312329/2019-9), São Gabriel, RS, \\ Brasil
}

Corresponding author: I.R. Carvalho

E-mail: carvalho.irc@gmail.com

Genet. Mol. Res. 19 (2): gmr18181

Received October 16, 2018

Accepted March 31, 2020

Published April 30, 2020

DOI http://dx.doi.org/10.4238/gmr18181

\begin{abstract}
Genetic improvement of soybean involves various biometric techniques and genomic tools. Controlled hybridization is an indispensable tool of the researcher; however, considering the complexity of the process, floral sensitivity and a strong effect of environmental conditions, the procedure is difficult to control. The objective of this work was to define the optimal periods for artificial hybridization of soybean, in order to maximize the number of seeds formed, and to understand the relationships between the agronomic characteristics of the parents and progenies. The study was carried out in Campos Borges, Rio Grande do Sul, Brazil, during the agricultural years of 2013, 2014, 2015, 2016, 2017 and 2018. The crosses were made during the initial period of flowering of the culture in the greenhouse, totaling 498 directed crosses. There was considerable variability in the number of crosses successfully made, in seed number and viability, and in the crossing index. The
\end{abstract}


efficiency of obtaining heterozygous soybean seeds was $13.8 \%$ using planned crosses under controlled conditions. The optimum period to maximize the number of seeds was from 8:15 to 9:45 AM, the number of seeds being inversely proportional to the advance in the day hours. The flower color and the growth habit of the parents express a similar tendency as the time of the cross is determinant for the success of this stage of breeding.

Key words: Glycine max; Soybean breeding; Controlled crossings

\section{INTRODUCTION}

Soybean (Glycine max) is one of the main cultivated leguminous species, having a wide range of purposes in the food sector, both human and animal, and as an alternative for the production of biodiesel (Sediyama et al., 2005). Brazil ranks as the second largest soybean producer in the world, only behind the United States of America; 35.2 million hectares were sown in the 2017/2018 agricultural crop year, with a Brazilian national average productivity of $3382 \mathrm{~kg} \cdot \mathrm{ha}^{-1}$, with production of approximately 118.8 million tons of grain (CONAB, 2018).

Due to the need to increase grain yield and consequently to leverage the soybean production chain, many breeding programs are aimed at obtaining stable and adaptable ideotypes in the diverse Brazilian soybean-growing regions. There is a a wide distribution of this crop, with heterogeneity in the edaphoclimatic conditions that guide the development of genotypes destined to constantly meet the needs of the consumer market; these must present high grain yields, tolerance to biotic and abiotic stresses, and be stable and nutritionally superior (Carvalho et al., 2017).

Currently, soybean breeding programs use techniques based on genetics, physiology, statistics, biotechnology and bioinformatics. However, the germplasm selection process becomes crucial to the breeding program, since it is based on the definition of the criteria for selection of the parents, hybridization techniques, size of segregating populations, identification and selection of superior and transgressive families, as well as the choice of the appropriate conduction method to be used; appropriate planning of this process can minimize costs, since it isexpensive to develop superior genotypes (Alard, 1971).

Among the stages of a breeding program, the peculiarities of the hybridization process are considered, selection of the best flowers to emasculate, characteristics of the flower in terms of size and coloring, as well as the definition of the best time of the day for performing the artificial hybridization, and that their success maximizes the number of fertilized, formed and viable F1s seeds (Borém, 1999). This will potentiate the magnitude of the heterozygous constitutions of the program in the crossing steps, and consequently increase the probability of gene and allelic recombinations that result in phenotypically superior genotypes for the characters of agronomic interest (Carvalho et al., 2017).

Procedures that elucidate the relevance of the effects of the crossing time, number of F1 seeds produced, characteristics of the parents regarding flowers, growth habit and relative maturity group of the parents are still scarce. Our objective was to define the optimal periods for artificial hybridization of soybean, in order to maximize the number of 
seeds formed, and to understand the relationships between the characteristics of the parents and the efficiency of the recombinations.

\section{MATERIAL AND METHODS}

The study was carried out in Campos Borges, Rio Grande do Sul, Brazil, at the geographic coordinates: $28^{\circ} 53^{\prime} 10^{\prime \prime}$ South and 52 $59^{\prime} 55^{\prime \prime}$ West, with an altitude of $513 \mathrm{~m}$, during the agricultural years of 2013, 2014, 2015, 2016, 2017 and 2018. It was conducted in a greenhouse with dimensions of $5 \times 6 \times 3$ meters, covered by transparent plastic film with a thickness of 200 microns.

In a standard way, in all agricultural years, the sowing of the parents was carried out during the first fortnight of October (first epoch) and in the first fortnight of November (second epoch), in order to allow maximum similarity between the flowering of the contrasting parents. The seeds were sown in polyethylene containers containing $22 \mathrm{~cm}^{3}$ of soil characterized as Dark Red Latosol (Steck, 2008), and these were arranged at depth of three centimeters. For each container, 10 seeds of the respective parent were used. After the establishment of the seedlings, they were submitted to thinning, leaving only three plants suitable for growth and development. The management was performed according to the needs of the crop, in order to minimize the biotic stressor effects in the experiment results.

Some criteria were established for the choice of the parents to be used, being: Value per se: this criterion is based on the additive genetic fraction among the parents, that is, the average expected value of the characters of agronomic interest. Contrasting parents are sought to maximize the expression of the characteristics in the progeny and thus to obtain transgressive families (Pandini et al., 1997); Genealogy of the parents: based on the a priori knowledge of the performance of the parents focused on high grain yields, tolerance and or resistance to biotic and abiotic stresses (Carvalho et al., 2017); Combinatorial ability: based on the possibility of identifying and selecting a combinatorial ability between the parents; Phenotypic markers: based on the phenotypic expression of the characteristics of agronomic interest (Toppa and Jadoski, 2013), characters that show high heritability, are easy to measure and are little influenced by environmental differences are searched (Vernetti and Vernetti Junior, 2009).

According to these criteria, flower color (FC), growth habit $(\mathrm{GH})$ and relative maturity group (MG) were selected as the main contrasting descriptors to differentiate the parents and evaluate the effects on the hybrid combinations. The FC is expressed in the colors white (allele w1) and purple (allele W1); it can be defined as a qualitative character where any change in its tonality is due to the minimal effects of the growing environment; the GH is present in allelic forms of complete dominance (DT gene), which represents the indeterminate growth habit, and the recessive allelic forms (dt gene) represent the determined growth habit, as for the semi-determined growth habit comes from epistatic actions and expression of the DT2 gene (Bernard, 1972; Thompson et al., 1997; Vernetti and Vernetti Junior, 2009) As regards the MG, it is defined according to the sequence of short days and critical photoperiod for the beginning of flowering of the genotypes, thus, the maturation groups used correspond to $4.8 ; 5.2 ; 5.3 ; 5.4 ; 5.5 ; 5.6 ; 5.8 ; 5.9 ; 6.0 ; 6.1 ; 6.2 ; 6.3$; $6.4 ; 6.5 ; 6.6 ; 6.7$ e 6.8 .

\section{Procedures involved in the hybridization of soybean}


Flower selection: it was opted to use flowers located on the main stem of the plant (flowers to be emasculated), from where the pollen donor flowers were collected.

Emmasculation: emasculation consists of the removal of the male androceutic (fillets and anthers) of the hermaphrodite flower, it is recommended that the gyneum remain intact, so as not to compromise the fertilization and the formation of the hybrid seeds. This procedure stands out due to the mechanism of cleistogamy, where stigma fertilization occurred prior to exposure and opening of the petals, and it is vital to identify the specific emasculation point to prevent self-fertilization.

Pollen collection: it was carried out using three flowers located in the branches of the paternal genitor, aiming to minimize the heterogeneity of the pollen maturity and the opening of the anthers.

Pollination: This procedure occurs in the emasculated flowers, where the pollen (paternal genitor) is placed on the stigma (maternal parent), using extra-fine needles and tweezers.

Identification of the cross: based on the simple genealogy used in the crossing, for this, a numerical sequence was used representing the parents, date and time of the crossing.

\section{Measured characters}

Time of crossing (HC): identification of the exact moment of the crossing, result in units of hour.

Number of seeds formed (NSF): the counting of the magnitude of viable seeds formed at the crossing was evidenced, resulting in units.

Index of establishment (IE): the ratio between the number of legumes formed with viable seeds and the magnitude of crosses made per agricultural year, results as percentages.

The data obtained were submitted to the diagnosis of discrepant values for the characters of interest. Afterwards, they were submitted to frequency analysis in order to identify the formation of phenotype classes. Then, the linear correlation was calculated, in order to determine the trend of association between the characters, with the significance based on the t-test at $5 \%$ probability. The phenotypic matrix was submitted to the mean Euclidean algorithm where the genetic distances matrix was elaborated, stratifying the tendencies for flower color, growth habit and the relative maturation group of the soybean. Subsequently, dendrograms were elaborated to show the dissimilarity of the sources of variation based on the Unweighted Pair Group Method with Arithmatic Mean (UPGMA) and the relative contribution of the characters to the differentiation of the studied sources of variation. The statistical analyzes were performed in the software Genes (Cruz, 2013) and Rbio (Bhering, 2017).

\section{RESULTS}

The results obtained in this study comprised six agricultural years with hybridizations, totaling 498 directed crosses (Table 1), according to the needs and criteria previously defined by the research, in order to increase variability, using contrasting parents. We observed considerable variability in the number of successful crosses, seed number and viability, as well as effects on the crossing index of establishment (IE). This 
variability is due to different abiotic and biotic factors, acting in a singular, synergistic or antagonistic way.

Table 1. Hybridizations of soybean performed in the agricultural years of 2013, 2014, 2015, 2016, 2017 and 2018 based on the number of crosses performed (NC), viable crosses that generated heterozygous seeds F1s (NP), and index of establishment (IE), performed through the relationship between number of crosses performed and heterozygous F1 seeds formed.

\begin{tabular}{lrrr}
\hline Agricultural years & NC & NP & IE \\
\hline 2013 & 34 & 3 & 8.82 \\
2014 & 218 & 32 & 14.67 \\
2015 & 65 & 8 & 12,30 \\
2016 & 59 & 3 & 5.08 \\
2017 & 71 & 17 & 23.94 \\
2018 & 51 & 6 & 11.76 \\
Total & 498 & 69 & 13.85 \\
\hline
\end{tabular}

* All procedures followed standard protocol in the six-year agricultural study.

The growing environment comprises many disturbing and potentially disturbing traits acting throughout the soybean growth and development process under artificial conditions. The incidence of solar radiation, water deficits and temperature and air relative humidity fluctuations are characterized as potentially disturbing actions where the researcher can act subtly to minimize its effects. The incidence of diseases, insect pests and nutritional deficiencies may be easier to control through preventive actions when soybean is grown in a protected environment (Hartman et al., 2005).

The phenotypic expression of the characters of agronomic interest is due to the ability of the genotype to express its genetic constitution against the influences of the environment during the soybean cycle. However, intrinsic characteristics of the genotype such as growth habit, relative maturation group and flower color are considered qualitative, with high heritability, low environmental effects, discrete distribution, few formed phenotype classes and abrupt intervals, being considered as phenotypic markers necessary for the selection of parents and superior progenies. In this context, it is crucial to understand the relationships between the parent plants and the ability to donate and receive pollen, tolerance to artificial hybridization, sporophytic and gametophytic compatibility, as well as viability of the heterozygous seeds produced (Carvalho et al., 2017).

In this study, 498 artificial hybridizations were performed over the six years (2013 to 2018). In 2014 and 2016 the largest numbers of artificial hybridizations were made; this was possible due to the concomitance of the maternal and paternal parents' flowerings, labor availability and the indoor and outdoor climatic conditions of the greenhouse (Table 1). The index of establishment (IE) showed variability ranging from 5.1 to $23.9 \%$, being considered of low magnitude, but this behavior is justified because it is estimated with a denominator based on the number of viable heterozygous $\mathrm{F}_{1 \mathrm{~s}}$ seeds.

It is therefore defined that this procedure is difficult to perform in a soybean breeding program, with the general average of about $14 \%$, with increasing need to optimize these results in order to increase the magnitude of heterozygous constitutions, segregating populations and families, as well as the probability of obtaining superior genotypes. The index of establishment refers to the efficiency of the breeder in detecting the point to make the artificial crossing, the technique used, as well as the interaction between floral, genetic 
and environmental mechanisms may modify the response of this procedure. The erroneous identification of the optimal period, injuries to carpels, nutritional stresses, and allelic complementarity may influence seed formation or abscission of flowers and pods during the reproductive period (Keen, 1990).
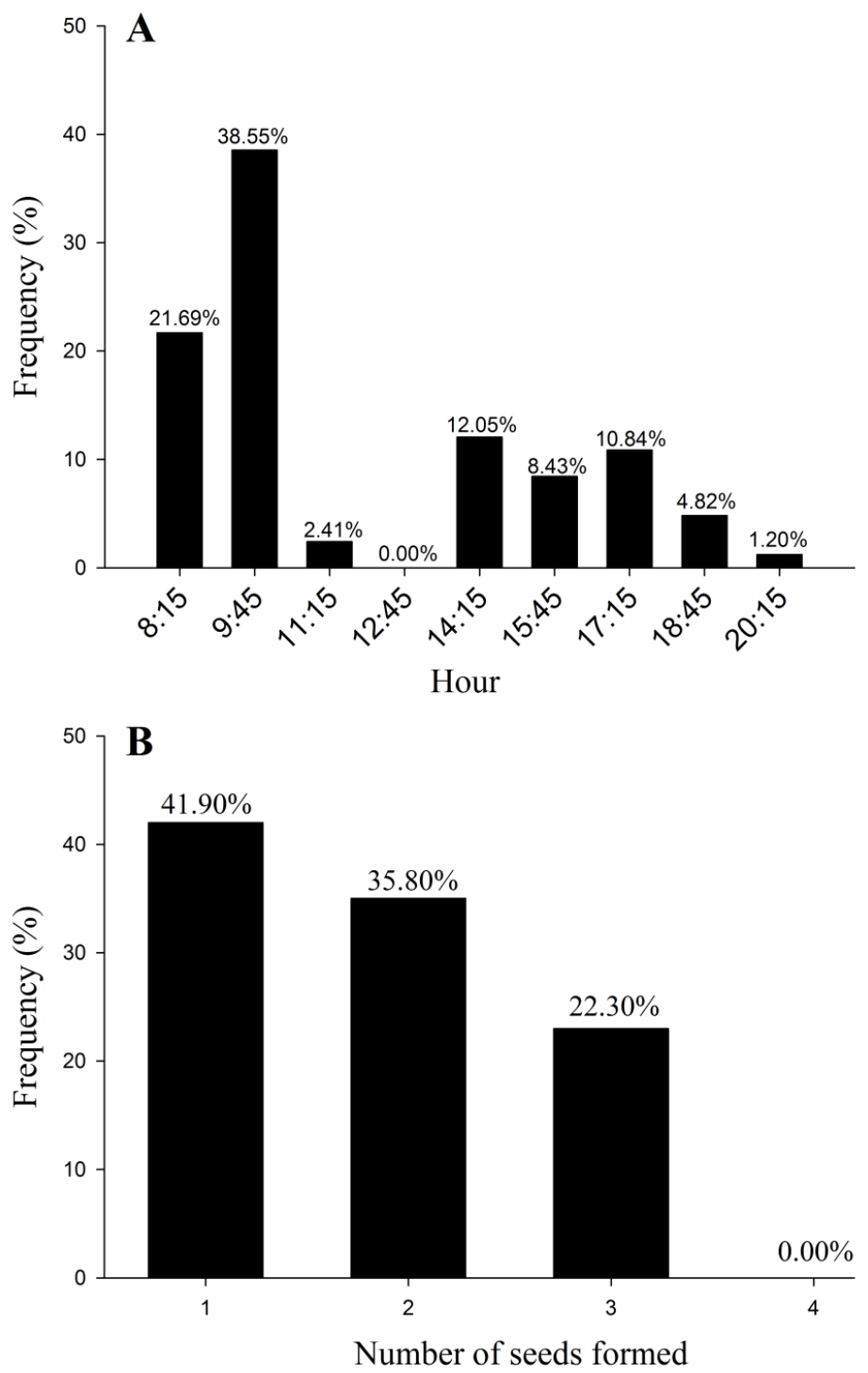

Figure 1. Relative frequency of successful hybridizations of soybean as a function of the time of crossing (A), and number of heterozygous seeds formed (B), for the six agricultural years of study.

Stratification of the crossing time (Figure 1A) was used to determine the best period for the hybridization, to maximize the number of heterozygous seeds. The oscillation of the air temperature, solar radiation incidence and relative air humidity oscillates during the day, 
due to this the greater rates of the index of establishment (IE) occurred when the hybridization procedure was carried out between 8:15 and 9:45, this space of 90 minutes reflected in $60.21 \%$ success in the hybridizations performed, which is the best period to increase the efficiency of the breeding program. The higher efficiency of viable seed formation was evident in the class corresponding to the period of 9:45 (38\%), due to the mild temperature and relative humidity conditions in the period.

The soybean flower is hermaphroditic, cleistogamic with reduced dimensions, which may hinder the artificial hybridization process, mainly due to mechanical injuries due to the emasculation process and errors in the pollination stages. The process of germination of the pollen grain at the end of the stigma is due to the physiological and metabolic responses of substances (Gazzoni, 2017), showing the maturity of gynaecine and the availability of pollen. Research by Cruden (2000), defines that the nutritional conditions of the plant determine the quality of the pollen produced. Studies by Gazzoni (2017) point out that plants under ideal environmental conditions express higher seed production due to adequate pollination, fertilization and maintenance of fertilized flowers.

Pods with only one viable heterozygous seed present superiority to total pods formed, where $41.9 \%$ of the artificial soybean hybridizations result in pods with only one seed (Figure 1B). Injuries caused by the emasculation process can result in a decrease in the frequency of pods with two, three or four seeds formed. In this context, maximizing the magnitude of $F_{1 s}$ seeds in the soybean breeding program can be obtained by increasing the number of crosses performed during the optimum period of the day, or together increasing the probability of obtaining pods with more seeds formed.

The search for understanding the relationship between specific parent-based crosses based on markers and phenotypic information becomes relevant. For breeders the efficient choice of parents is one of the most difficult tasks of breeding, as well as understanding which of these should be maternal or paternal, what are the reciprocal effects, maternal effects or heritages, genetic distance, nuclear, cytoplasmic of mitochondria and chloroplasts contribution (Pulcinelli, 1992).

The general and stratified linear associations were determined regarding the specific characteristics of the parents based on flower color, growth habit and relative maturation group. In this way, the time of crossing was correlated with the number of seeds formed. Significant inverse association for these attributes only in the stratification for the relative maturation group ( $\mathrm{r}$ : -0.25). In this way, it is verified that the advance of the period of the day that the crossing was carried out there was the decrease of the number of seeds formed. This is still dependent on the relative maturation group of the parents used, because as it is expressed higher, there is a lower probability of formation of viable heterozygous seeds, a behavior that did not prove to be similar for the stratification as to the color of the flower and habit of growth.

The relative contribution of the characters by the method of Singh (1981), make it possible to determine which characters most influence the distinction between groups of associations. Thus, the color of the flowers (Figure 2A) and the growth habit (Figure 2B) of the soybean showed that at the time of crossing, the greatest contribution was made to differentiate the responses from the artificial hybridizations, being 55.74 and $58.87 \%$ respectively. However, when stratifying the relative maturation group of the parent (Figure $2 \mathrm{C}$ ), the number of seeds formed contributed $60.55 \%$, being defined as the most important and of high variability. 

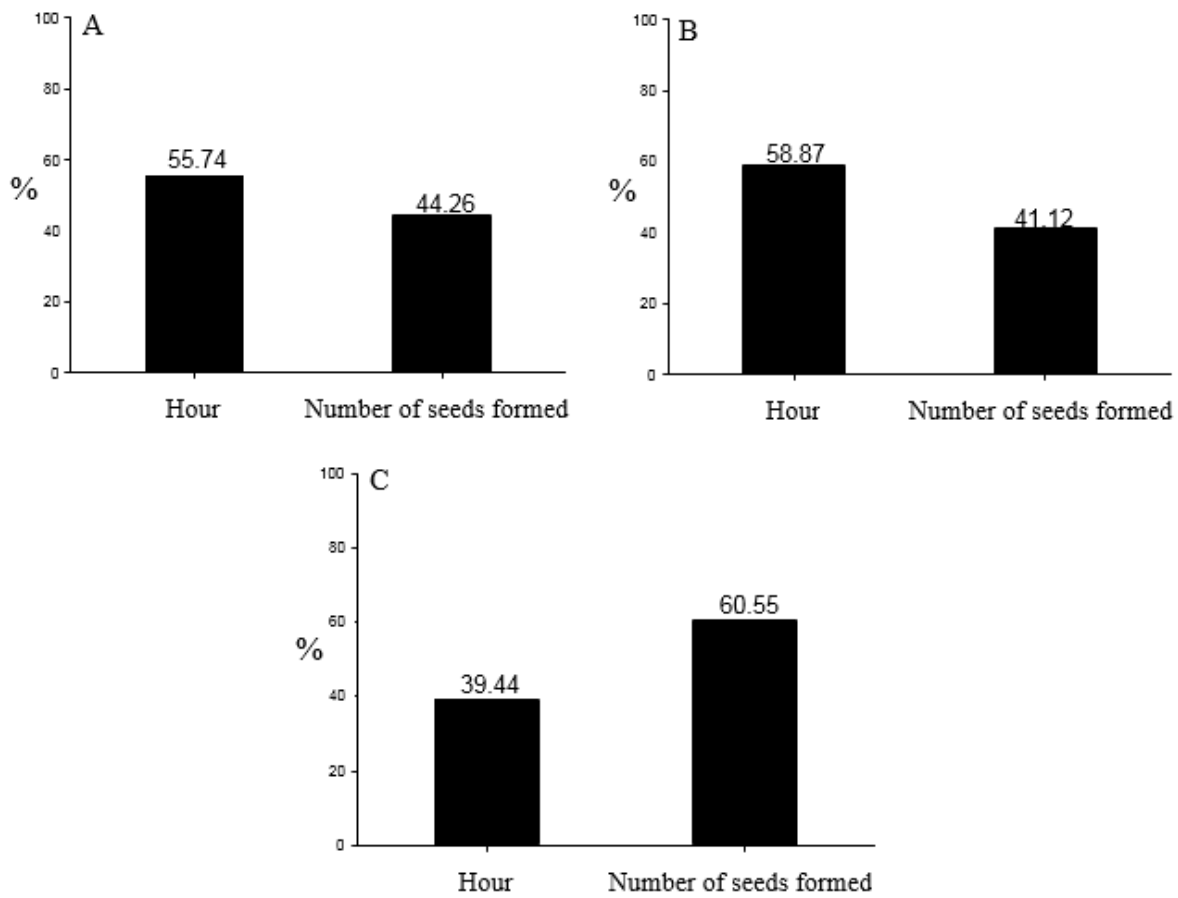

Figure 2. Relative contribution of the stratified characters to the flower color of the soybean parents (A), growth habit of the parents (B), and relative maturation group (C), based on the time of crossing and number of seeds formed measured during the six years of study.

With emphasis on the flower color of the parent (Figure 3), these associations were segregated into three groups. Pattern I is formed by hybridizations using maternal parents of white flowers crossed with paternal parents with white flowers (WC x WC) and maternal parents with purple and paternal flowers with purple flowers (PC x PC), in this context, the use of the parents with similar flower coloration result in similarity of the response regarding the crossing period, number of seeds formed and index of establishment. When revealing a contrasting combination of maternal and paternal parents with white and purple flowers (WC x PC and PC x WC), they are found to cause considerable polymorphism in the evaluated characters.

In stratifying the hybridization trends regarding the growth habit of the parents used, it is defined that (Figure 4) the use of the maternal and paternal parents with semideterminate growth habit (SDGH $x$ SDGH), as well as maternal parent with indeterminate growth habit crossed with paternal genitor with determinate growth habit (IGH x DGH) evidences similar pattern when at the period of realization of the crosses and magnitude of the seeds formed. Another defined pattern is based on the maternal parents of the semideterminate growth habit crossed with the determinate growth habit (SDGH x DGH), as well as maternal and paternal parents with indeterminate growth habit (IGH x IGH). The other heterozygous combinations formed the third standard being these IGH x SDGH, DGH $\mathrm{x}$ IGH and SDGH $\mathrm{x}$ IGH. 


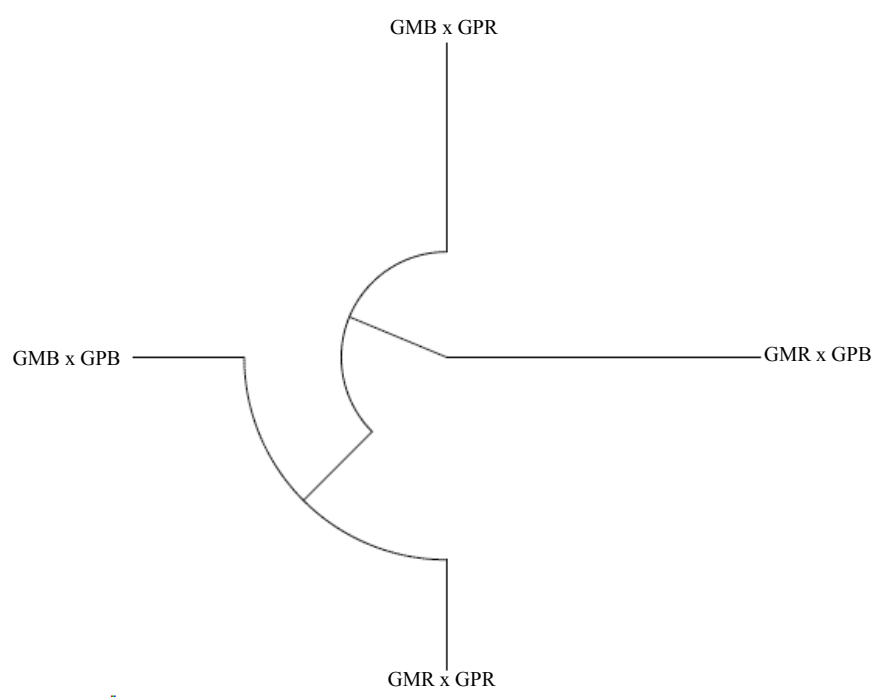

Figure 3. Dendrogram based on the genetic distance obtained by the mean Euclidean matrix and UPGMA grouping method, where the phenotypic marker of the soybean parents based on the flower color was stratified, the combination being identified by the flower coloration of the maternal parent (PC: purple flower and WC: white flower) crossed with the paternal parent (PC: purple flower and WC: white flower).

It was possible to classify the 498 crosses directed in 51 specific classes using the relative maturation groups $4.8,5.2,5.3,5.4,5.5,5.6,5.8,5.9,6.0,6.1,6.2,6.3,6.4,6.5,6.6,6.7$, 6.8 (Figure 5). Where the maternal parent $x$ paternal genitor was ordered, being established that according to the time of crossing, number of seeds formed and index of establishment was possible to represent ten specific crosses profiles when stratification of maturation groups of the parents.

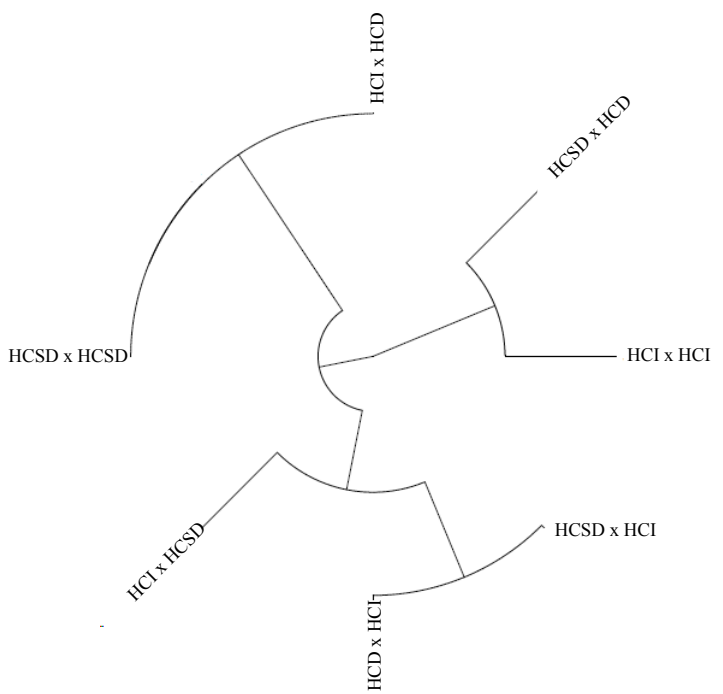

Figure 4. Dendrogram based on the genetic distance obtained by the mean Euclidean matrix and UPGMA grouping method, where the phenotypic marker of the soybean parents based on the soybean growth habit was stratified. The combination was identified by the growth habit of the maternal parent (determinate growth habit: DGH, semideterminate growth habit: SDGH, indeterminate growth habit: IGH) crossed with the paternal parent (determinate growth habit: DGH, semi-determinate growth: SDGH; indeterminate growth habit: IGH). 


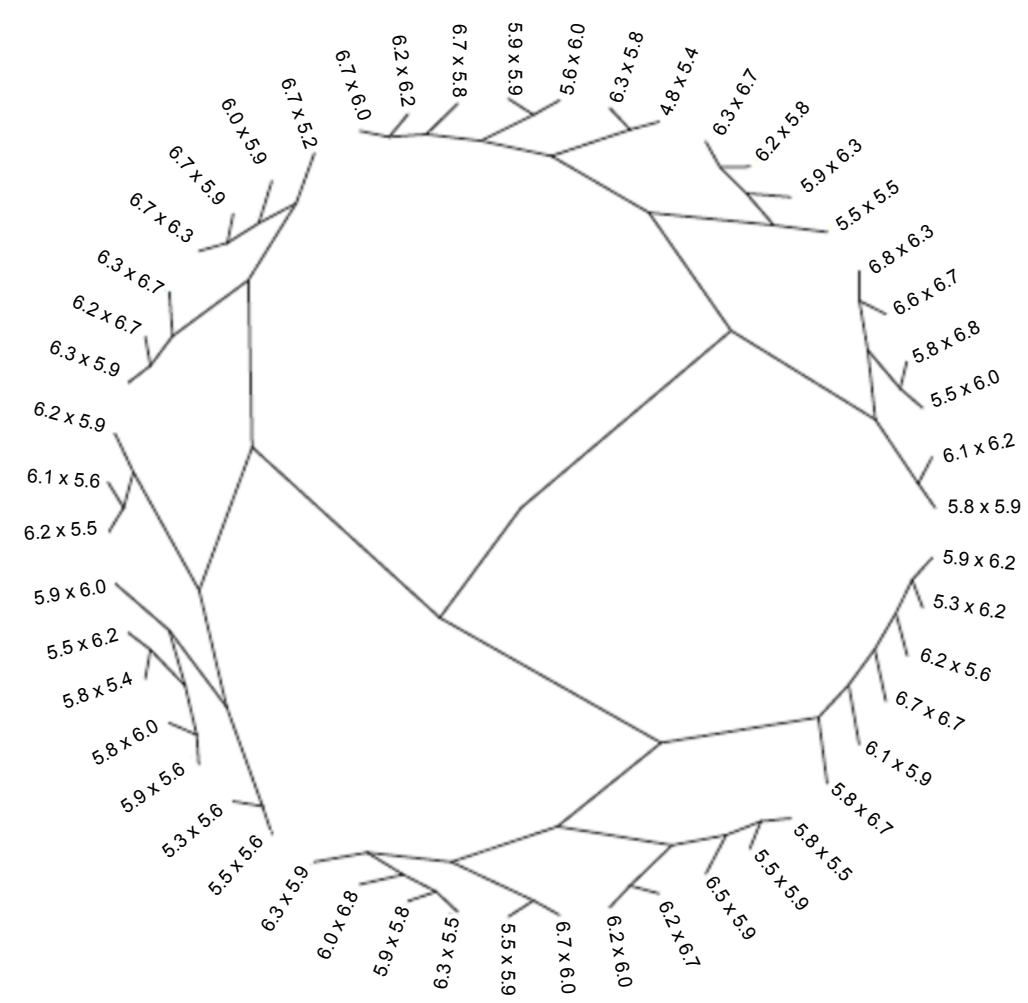

Figure 5. Dendrogram based on the genetic distance obtained by the mean Euclidean matrix and UPGMA grouping method, where the phenotypic marker of the soybean parents based on the relative maturation group was stratified. The combination was identified by the relative maturation group of the maternal parent $(4.8,5.2$, $5.3,5.4,5.5,5.6,5.8,5.9,6.0,6.1,6.2,6.3,6.4,6.5,6.6,6.7,6.8)$ crossed with the paternal parent $(4.8,5.2,5.3$, $5.4,5.5,5.6,5.8,5.9,6.0,6.1,6.2,6.3,6.4,6.5,6.6,6.7,6.8)$.

This research had six years of research carried out exclusively for the artificial hybridization of soybean, being possible to define the ideal period for the crossing and its effects to the number of seeds formed, as well as the success rate of the hybridizations. At the same time, associations and profiles of specific crosses were determined based on the phenotypic markers of the parents. These univariate and multivariate trends are likely to be employed in future studies and soybean breeding programs that aim to potentiate heterozygous recombination and genetic variability.

\section{CONCLUSIONS}

The efficiency of obtaining heterozygous soybean seeds was $13.8 \%$ using planned crosses under controlled conditions. The optimum period to maximize the number of seeds wass from 8:15 to 9:45, the magnitude of seeds being inversely proportional to the advance of the day hours.The flower color and the growth habit of the parents expressed a similar tendency in which the time of the crossing is determinant for the success of this stage of breeding. 


\title{
ACKNOWLEDGMENTS
}

We thank the IRC Soy Genetic Improvement Program, Regional University of the Northwest of the State of Rio Grande do Sul (UNIJUÍ), National Council for Scientific and Technological Development $(\mathrm{CNPq})$ and the Coordination for the Improvement of Higher Level or Education Personnel (Capes) for their support.

\section{CONFLICTS OF INTEREST}

\author{
The authors declare no conflict of interest.
}

\section{REFERENCES}

Alard RW (1971). Princípios do melhoramento genético das plantas. São Paulo: Edfard Blucher.

Bernard RL (1972). Two genes affecting stem termination in soybeans. Crop Sci. 12: 235-239.

Bhering LL (2017). Rbio: A Tool for Biometric and Statistical Analysis Using The R Platform. Crop Breed. Appl. Biotechnol. 17: 187-190. http://dx.doi.org/10.1590/1984-70332017v17n2s29.

Borém A (1999). Hibridação artificial de plantas. Viçosa, MG. UFV, 443-462p.

Carvalho CGP, Arias CAA, De Toledo JFF, De Almeida LA, et al. (2002). Interação genótipo x ambiente no desempenho produtivo da soja no Paraná. Pesq. Agropec. Bras. 37: 989-1000. 10.2135/cropsci1972.0011183X001200020028x

Carvalho IR, Nardino M and Souza VQ (2017). Melhoramento e Cultivo da Soja. 1ed. Porto Alegre: Cidadela, 2: 29-46.

CONAB - Companhia Nacional de Abastecimento. (2018). Acompanhamento da safra Brasileira de grãos. Safra 2017/18. 5(9) nono levantamento. Brasília.

Cruden RW (2000). Pollen grains: why so many? Plant. Syst. Evol. 222(1-4): 143-165.

Cruz CD (2013). Genes: a software package for analysis in experimental statistics and quantitative genetics. Acta Sci. Agron. 35(3): 271-276.

Gazzoni DL (2017). Soja e abelhas. Brasília, DF: Embrapa.

Hartman GL, Miles MR and Frederick RD (2005). Breeding for resistance to soybean rust. Plant Dis. 89(6), 664-666.

Keen NT (1990). Gene-for-gene complementarity in plant-pathogen interactions. Annu. Rev. Genet. 24(1): 447-463. 10.1146/annurev.ge.24.120190.002311.

Pandini F, Carvalho FIF and Barbosa Neto JF (1997). Avaliação da variabilidade genética em triticale para ciclo e estatura de planta obtida a partir de mutações induzidas e cruzamentos artificiais. Pesq. Agrop. Gauc. 3: 55-61.

Pulcinelli CE (1992). Herança do teor de proteína em soja. Masters Thesis, Universidade de São Paulo.

Sediyama T, Teixeira RC and Reis MS (2005). Melhoramento da soja. In Borem (Ed.). Melhoramento de espécies cultivadas. 2 ed. Editora UFV, Vicosa. Pp. 553-603.

Singh D (1981) The relative importance of characters affecting genetic divergence. Indian J. Genet. Pl. Br. 41: 237-245.

Thompson JA, Bernard RL and Nelson RLA (1997). Third allele at the soybean dt1locus. Crop Sci. 37: 757-762. http://dx.doi.org/10.2135/cropsci1997.0011183X003700030011x.

Toppa EVB and Jadoski CJ (2013). O uso de marcadores moleculares no melhoramento genético de plantas. Sci. Agrar Paran. 12: 1-5. http://dx.doi.org/10.1818/sap.v12i1.4552.

Vernetti FJ and Vernetti Junior FJ (2009). Genética da soja, caracteres qualitativos e diversidade genética. EMBRAPA, $1^{\mathrm{a}} \mathrm{ed}$. 